\title{
PÓS-GRADUAÇÃO E PESQUISA: A EDUCAÇÃO ESPECIAL COMO TEMA DAS DISSERTAÇÕES E TESES EM DOIS PROGRAMAS DE UNIVERSIDADES PÚBLICAS DO PARÁ
}

\author{
GRADUATE COURSE E PESQUISA: A EDUCAÇÃO ESPECIAL COMO TEMA DAS \\ DISSERTAÇÕES E TESES EM DOIS PROGRAMAS DE UNIVERSIDADES PÚBLICAS DO \\ PARÁ
}

\author{
Joaquina Ianca dos Santos Miranda ${ }^{1}$ \\ Ariana Souza Carneiro ${ }^{2}$ \\ Bianca Marinho de Souza ${ }^{3}$ \\ Kátia Maria Barros de Miranda ${ }^{4}$ \\ Luciano Tadeu Corrêa Medeiros ${ }^{5}$
}

\begin{abstract}
RESUMO: O trabalho apresenta dados de um mapeamento das teses e dissertações que tem como tema central a Educação Especial e que foram apresentados em dois programas de pósgraduação em Educação, um ofertado pela Universidade Federal do Pará e outro pela Universidade do Estado do Pará. O objetivo é identificar qual a frequência do tema Educação Especial nos trabalhos produzidos pelos candidatos aos títulos de Mestre e Doutor desses programas e, assim, verificar em quais segmentos alinham-se as discussões do tema em questão. $\mathrm{O}$ artigo foi desenvolvido a partir da abordagem quanti-qualitativa e utilizou, em sua técnica, o mapeamento sistemático dos trabalhos apresentados nos programas de pós-graduação indicados, que adotou como critério o recorte temporal de 2016 a 2019 e a incidência das problemáticas trabalhadas no âmbito da Educação Especial. Simultaneamente, foi desenvolvida uma pesquisa bibliográfica para a extração da base teórica sobre as questões que envolvem o tema Educação Especial. Os resultados apontam a necessidade do desenvolvimento de pesquisas na perspectiva da Educação Especial em seus diversos segmentos, identificam lacunas mediante a escassez de trabalhos desenvolvidos sob o prisma dessa temática e mostram, ainda, a necessidade de se estimular a produção científica nessa área, no propósito de ampliar as possibilidades de possíveis soluções de problemas emergentes relacionados a essa demanda.
\end{abstract}

Palavras-chave: Educação Especial. Programas de pós-graduação. Especialização. Pesquisa.

ABSTRACT: The work presents data from a mapping of the theses and dissertations that have Special Education as their central theme and that was presented in two graduate programs in Education, one offered by the Federal University of Pará and the other by the State University

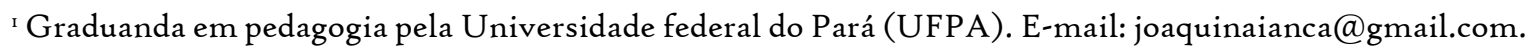

${ }^{2}$ Graduanda em pedagogia pela Universidade Federal do Pará (UFPA).E-mail: arizouzacı2o@gmail.com.

3Graduanda em pedagogia pela Universidade Federal do Pará (UFPA).E-mail: bmarinhozors@gmail.com.

${ }_{4}^{4}$ Graduada em pedagogia pela Universidade Federal do Pará (UFPA) e discente pela Secretaria Municipal de Educação - São Miguel do Guamá - Pará (SEMED). E-mail:kathiademiranda@gmail.com.

${ }^{5}$ Graduando em pedagogia pela Universidade Federal do Pará (UFPA). E-mail: lucianomedeiros2602@gmail.com. 
of Pará. the objective is to identify the frequency of the Special Education theme in the works produced by candidates for the titles of Master and Doctor of these programs and, thus, to verify in which segments the discussions of the theme in question are aligned. The article was developed from the quantitative and qualitative approach and used, in its technique, the systematic mapping of the works presented in the indicated graduate programs, which adopted as a criterion the time frame from 2016 to 2019 and the incidence of the problems worked on Special Education. Simultaneously, bibliographic research was developed to extract the theoretical basis on the issues involving the Special Education theme. The results point to the need for the development of research from the perspective of Special Education in its various segments, identify gaps due to the scarcity of works developed under the prism of this theme and also show the need to stimulate scientific production in this area, with the purpose to expand the possibilities of possible solutions to emerging problems related to this demand.

KEYWORDS: Especial Education. Graduate programs. Specialization. Search.

\section{INTRODUÇÃO}

A Educação Especial, segundo a legislação brasileira, é uma modalidade de ensino que tem como principal objetivo dar suporte educacional para alunos que necessitam de um atendimento específico devido uma condição diferenciada (BRASIL, 1996), fazendo com que seja possível a materialização do aprendizado e desenvolvimento integral desses alunos (KASSAR, 20II). Do ponto de vista pedagógico, trata-se de uma forma de preparar professores e profissionais da educação, no intento de que se compreendam as necessidades de ações educacionais direcionadas especificamente à educação escolar dos alunos que apresentam qualquer deficiência física, sensorial, mental ou múltipla e, ainda, dos alunos com altas habilidades e superdotação (BRASIL, 1996; KASSAR, 20II; MAZOTTA, 2005).

A Educação Especial tem uma longa trajetória no contexto educacional brasileiro, apresentando indícios desde o século XIX, até se estabelecer como o elemento principal a ser utilizado nos processos educativos das pessoas com necessidades especiais de aprendizagem (MAZOTTA, 2005). Em meio a sua trajetória, importantes discussões têm surgido no meio acadêmico sobre o fazer do educador como profissional especialista nessa modalidade de educação e as ações que têm sido desenvolvidas por esses para o atendimento escolar dos alunos e suas especificidades educativas (KASSAR, 2011; MARQUES et, al, 2008). Observa-se que tais discussões têm diversificado a pesquisa em Educação Especial e ampliado o debate sobre o assunto e o resultado percebido - de forma positiva - é a vasta produção de conhecimento relacionado a esse tema e às questões que o envolvem (MAZOTTA, 2005; NAZARI, 2019; MARQUES et al, 2008).

A ampliação das produções acadêmicas sobre esses conhecimentos contribui para que essa modalidade de ensino seja melhor trabalhada e os sujeitos que necessitam dos conhecimentos 
especializados da Educação Especial tenham, por consequência, um melhor atendimento educativo (NAZARI, 2019), pois as vastas possibilidades na formulação didática e na prática pedagógica desse profissional podem ampliar as estratégias para o atendimento dessa demanda (MARQUES et al, 2008; MAZOTTA, 2005) e, ainda, evidenciar algumas situações paralelas que, de alguma forma, podem tornar-se um obstáculo no aprendizado e desenvolvimento dos alunos (KASSAR, 20II; NAZARI, 2019). Essas situações muitas vezes não são percebidas no entorno educacional dos mesmos, dentre as quais podemos citar os elementos ligados à condição social, cultural e econômica desses alunos, por isso, evidencia-se a importância das discussões sobre o tema (KASSAR, 2011).

Importa considerar que as propostas de especializações, mestrados e doutorados ofertadas pelos programas de pós-graduação são potenciais instrumentos para a ampliação das discussões (MARQUES et al, 2008) e, ainda, para o aprimoramento de questões levantadas por esses programas no que se refere à Educação Especial. Nessa perspectiva, essas discussões tornam-se determinantes para a concretude da produção de conhecimentos diversificados nessa área (NAZARI, 2019). Dentro desses programas, damos destaque à expansão dos Programas de Pós-graduação stricto sensu - mestrados e doutorados -, destinados à área da Educação, que tem se estabelecido no Brasil, porém, esses programas, por sua vez, são direcionados à formação de docentes que irão atuar no ensino superior (NAZARI, 200I). Cabe ressaltar, ainda, a qualidade desses programas, pois os mesmos têm sido avaliados através de critérios cada vez mais refinados e rigorosos, feitos por entidades como a Fundação Coordenação de Aperfeiçoamento de Pessoal de Nível Superior (CAPES) do Ministério da Educação (MEC), e têm atraído os olhares de pesquisadores que, através de parâmetros científicos, têm avaliado o material produzido nesses programas (MARQUES et al. 2008).

Dessa forma, justifica-se a realização deste trabalho, visto que se compreende a necessidade de investigação das pesquisas de aprofundamento que se dedicam ao tema Educação Especial, assim como se entende necessário verificar a frequência com que foram desenvolvidas as pesquisas sobre esse tema nos anos delimitados e, ainda, como as questões relacionadas ao tema têm sido abordadas dentro dessa problemática. Por isso, buscou-se identificar qual a frequência do tema Educação Especial nos trabalhos desenvolvidos pelos candidatos aos títulos de Mestre e Doutor dos Programas de Pós-Graduação em Educação em duas das Universidades Públicas paraenses que oferecem o programa, para, assim, verificar se nas áreas temáticas abordadas nas teses e dissertações há as que tratam o assunto em questão. Para tanto, evidenciamos o seguinte questionamento: qual o volume de representatividade do tema Educação Especial e que problemáticas ligadas a elas foram trabalhadas nas teses e dissertações 
voltadas a essa modalidade de ensino que foram defendidas nesses dois Programas de Pósgraduação em Educação do Pará?

\section{CAMINHOS METODOLÓGICOS}

Para a produção do artigo, foi realizada uma pesquisa que utilizou simultaneamente a abordagem qualitativa e quantitativa, pois a combinação de dados quantitativos "[..] com dados oriundos de metodologias qualitativas, podem vir a enriquecer a compreensão de eventos, fatos, processos" (GATTI, 2004, p.I3). A pesquisa foi desenvolvida entre os meses de março e abril do ano de 2020 .

No processo de integração entre método qualitativo e quantitativo, foi realizada uma pesquisa bibliográfica para extração do aporte teórico de autores que tratam o tema Educação

Especial, pois é crucial entender que: “A mais importante dessas considerações, recolhida na própria natureza do assunto, consiste na necessidade, em todas as épocas duma teoria qualquer para ligar os fatos" (COMTE,I973. p.II). Assim, é ressaltada a necessidade de suporte epistemológico na argumentação para a produção de conhecimento, como declara Demo (2002, p. 352): "ressalto a autoridade do argumento, em desfavor do argumento de autoridade, preferindo, ostensivamente, a habilidade de fundamentar com coerência e consistência a textos epistemologicamente despreocupados".

Utilizou-se a técnica de mapeamento sistemático para o levantamento de teses e dissertações que se centravam no tema Educação Especial defendidas nos Programas de Pósgraduação em Educação (PPGED) ofertados pela Universidade Federal do Pará (UFPA) e Universidade do Estado do Pará (UEPA). Para Falbo (2018), os Mapeamentos Sistemáticos são estudos de ordem secundária, cuja metodologia segue um curso e um objetivo bem definido, que é a identificação, análise e interpretação dos resultados adquiridos que se relacionam com todas as questões que se referem à pesquisa, ao objeto central de observação ou fenômeno investigado. Segundo o autor, esses mapeamentos possibilitam a evidência de possíveis lacunas em determinada esfera de estudo, assim como nos permitem identificar e classificar a produção científica do tempo delimitado (FALBO, 2018).

Nesse sentido, para a realização desta técnica foram obedecidas as seguintes etapas: foi definida a estratégia de busca, a partir do acesso ao banco de dados online dos programas selecionados - PPGED UEPA, 2020; REPOSITÓRIO UFPA, 2020 -, em que se delimitou o período cronológico a ser mapeado - do ano de 2016 ao ano de 2019 - e optou-se como critério de seleção as dissertações e teses que tinham com o tema central a Educação Especial. Os dados obtidos foram sintetizados e posteriormente categorizados. A síntese do levantamento dos 
trabalhos utilizou as seguintes informações: programa onde o trabalho foi apresentado, identificação do nome do autor, título do trabalho, ano de defesa, tipo de trabalho - Teses ou Dissertações - e a categorização em área temática, sendo que a categorização dos temas foi organizada, na tentativa de expressar as relações mais peculiares nas tratativas dadas a Educação Especial nos trabalhos.

\section{RESULTADOS}

A partir do mapeamento realizado, foram identificadas as teses e dissertações que tinham seus temas centrados na Educação Especial e os eixos temáticos por elas trabalhados. Os resultados foram sumarizados em quadros e gráficos para evidenciar o cenário desse tipo de produção e sua representatividade em relação ao número total de trabalhos defendidos nos PPG. Inicia-se pelo quantitativo total da amostra analisada que se encontram expostos no quadro $\mathrm{I}$. Importa destacar que o doutorado do PPGED/UEPA ofertou a sua primeira turma no ano de 2019, com io vagas, no processo seletivo realizado em 2018 (PPGED UEPA, 2020). Por esse motivo, não há produções bibliográficas defendidas no período delimitado.

QUADRO I - Dissertações e Teses defendidas nos Programas de Pós-graduação no período de 2016 A 2019

\begin{tabular}{|c|c|c|c|}
\hline Instituição/programa & Dissertações & Teses & Total (PPGED) \\
\hline PPGED/UFPA & I21 & 78 & 199 \\
\hline PPGED/UEPA & 162 & - & 162 \\
\hline Total & 283 & 78 & 361 \\
\hline
\end{tabular}

Fonte: Elaboração dos autores.

Foram organizadas as informações relacionadas ao número total de monografias mapeadas e que se encontram no campo da Educação Especial dos dois programas de pós-graduação, essas informações encontram-se no quadro 2.

QUADRO 2 - Trabalhos com ênfase em Educação Especial (2016-2019)

\begin{tabular}{|c|c|c|c|}
\hline Programa & Dissertações & Teses & Parcial \\
\hline PPGED/UEPA & 6 & I & 7 \\
\hline PPGED/UFPA & I5 & - & 15 \\
\hline Total & $\mathbf{2 I}$ & $\mathbf{I}$ & $\mathbf{2 2}$ \\
\hline
\end{tabular}

Fonte: Elaboração dos autores.

Outros dados considerados importantes para se compor uma percepção mais ampla sobre o levantamento desses trabalhos são apresentamos no quadro 3. 
QUADRO $_{3}$ - Percentual de trabalhos com ênfase em Educação Especial (2016-2019)

\begin{tabular}{|c|c|c|c|}
\hline Natureza & PPGED/UEPA & PPGED/UFPA & Total \\
\hline Dissertações & $9,25 \%$ & $4,95 \%$ & $7,42 \%$ \\
\hline Teses & - & $1,28 \%$ & $1,28 \%$ \\
\hline Índice Geral & $9,25 \%$ & $3,51 \%$ & $6,09 \%$ \\
\hline
\end{tabular}

Fonte: Elaborado pelos autores.

Além destes quantitativos, considerou-se necessário identificar as teses e dissertações mapeadas apontando o seu respectivo autor, título, ano de defesa, tipo de monografia e área temática. A seguir, apresenta-se o quadro 4, referente ao PPGED/UFPA.

QUADRO $_{4}$ - Dissertações e Teses com tema Educação Especial apresentadas no período de 20219 à 2019 no Programa de Pós-graduação em Educação da UFPA

\begin{tabular}{|c|c|c|c|c|}
\hline Autor & Título & Ano & Tipo & Área Temática \\
\hline $\begin{array}{c}\text { Hulda Iza } \\
\text { Gonçalves de } \\
\text { Paula }\end{array}$ & $\begin{array}{c}\text { Adaptações curriculares e a inclusão } \\
\text { educacional da pessoa em situação de } \\
\text { deficiência: um estudo de caso em escolas } \\
\text { públicas localizadas no município de } \\
\text { Belém/Pa. }\end{array}$ & 2016 & DISS & $\begin{array}{c}\text { Educação Especial } \\
\text { e Currículo }\end{array}$ \\
\hline $\begin{array}{l}\text { Tatiana de } \\
\text { Castro } \\
\text { Oliveira }\end{array}$ & $\begin{array}{c}\text { Práticas pedagógicas inclusivas no } \\
\text { cotidiano da educação infantil na escola } \\
\text { de aplicação da } \\
\text { Universidade Federal do Pará }\end{array}$ & 2016 & DISS & $\begin{array}{c}\text { Práticas } \\
\text { pedagógicas para } \\
\text { inclusão na } \\
\text { Educação Infantil }\end{array}$ \\
\hline $\begin{array}{c}\text { Jarbas } \\
\text { Marcelino } \\
\text { Costa da Silva }\end{array}$ & $\begin{array}{c}\text { Educação inclusiva: um estudo } \\
\text { autobiográfico sobre o processo de } \\
\text { escolarização de um estudante com } \\
\text { deficiência visual }\end{array}$ & 2016 & DISS & $\begin{array}{c}\text { Educação de } \\
\text { deficientes visuais }\end{array}$ \\
\hline $\begin{array}{l}\text { Ana Paula de } \\
\text { Araújo Barca }\end{array}$ & $\begin{array}{c}\text { Subjetivação e escolarização de um aluno } \\
\text { surdo usuário de implante coclear: um } \\
\text { estudo de caso fundamentado na } \\
\text { perspectiva histórico- } \\
\text { cultural }\end{array}$ & 2017 & DISS & $\begin{array}{l}\text { Educação de } \\
\text { surdos }\end{array}$ \\
\hline $\begin{array}{l}\text { Marcia de } \\
\text { Fátima de } \\
\text { Oliveira }\end{array}$ & $\begin{array}{l}\text { Formação continuada para atuação } \\
\text { pedagógica inclusiva na educação infantil: } \\
\text { um estudo no sistema municipal de } \\
\text { ensino de Belém - Pará }\end{array}$ & 2017 & DISS & $\begin{array}{c}\text { Formação e } \\
\text { prática docente } \\
\text { para a } \\
\text { Educação Especial } \\
\text { e inclusão }\end{array}$ \\
\hline $\begin{array}{l}\text { Suelen } \\
\text { Tavares } \\
\text { Godim }\end{array}$ & $\begin{array}{l}\text { In/exclusão de pessoas com deficiência } \\
\text { no mercado de trabalho no estado do Pará }\end{array}$ & 2017 & TESE & $\begin{array}{c}\text { Educação especial, } \\
\text { inclusão e } \\
\text { trabalho }\end{array}$ \\
\hline $\begin{array}{l}\text { Mirian Rosa } \\
\text { Pereira }\end{array}$ & $\begin{array}{l}\text { Um estudo sobre a inclusão escolar e os } \\
\text { recursos financeiros para o atendimento } \\
\text { dos } \\
\text { alunos com deficiência, no município de } \\
\text { marabá-PA }\end{array}$ & 2019 & DISS & $\begin{array}{l}\text { Políticas públicas } \\
\text { de inclusão } \\
\text { educacional e } \\
\text { atendimento } \\
\text { especializado }\end{array}$ \\
\hline
\end{tabular}


Fonte: Elaborado pelos autores com base nas informações do Repositório Institucional da Universidade Federal do Pará (2020).

Nota-se que os trabalhos se distribuem em sete áreas temáticas distintas, com o mesmo percentual de representatividade em cada. Para o levantamento dos trabalhos relacionados ao PPGED/UEPA, foram organizadas da mesma forma as informações relativas a esse programa, apresentadas no quadro 5, a seguir.

QUADRO 5 - Dissertações e Teses com tema Educação Especial apresentadas no período de 20219 à 2019 no Programa de Pós-graduação em Educação da UEPA

\begin{tabular}{|c|c|c|c|c|}
\hline Autor & Título & Ano & Tipo & Área Temática \\
\hline $\begin{array}{l}\text { Carina da Silva } \\
\text { Mota }\end{array}$ & $\begin{array}{l}\text { Glossário visual bilíngue na educação de } \\
\text { surdos: estudo sociolinguístico na língua } \\
\text { brasileira de sinais volume I }\end{array}$ & 2016 & DISS & Educação de Surdos \\
\hline $\begin{array}{l}\text { Joana Célia do } \\
\text { Socorro Gomes de } \\
\text { Andrade Martins }\end{array}$ & $\begin{array}{c}\text { Lamparina para cegos: literatura acessível } \\
\text { na Amazônia }\end{array}$ & 2016 & DISS & $\begin{array}{l}\text { Educação Especial e } \\
\text { práticas de Leitura, } \\
\text { Escrita e linguagem/ } \\
\text { Educação de } \\
\text { deficientes visuais }\end{array}$ \\
\hline $\begin{array}{l}\text { Felipe Lisboa } \\
\text { Linhares }\end{array}$ & $\begin{array}{l}\text { Atendimento educacional especializado: } \\
\text { uma análise sobre a construção identitária } \\
\text { de professores que atuam na sala de } \\
\text { recursos multifuncionais }\end{array}$ & 2016 & DISS & $\begin{array}{l}\text { Formação e prática } \\
\text { docente para a } \\
\text { educação especial e } \\
\text { inclusão }\end{array}$ \\
\hline $\begin{array}{l}\text { Maria Valdeli } \\
\text { Matias Batista }\end{array}$ & $\begin{array}{c}\text { Saberes culturais de jovens e adultos com } \\
\text { deficiência de comunidades das ilhas de } \\
\text { Abaetetuba-PA }\end{array}$ & 2016 & DISS & $\begin{array}{c}\text { Educação especial e } \\
\text { Educação de Jovens e } \\
\text { Adultos (EJA) }\end{array}$ \\
\hline $\begin{array}{c}\text { Pamela do Socorro } \\
\text { Da Silva Matos }\end{array}$ & $\begin{array}{c}\text { Gestos de surdos e ouvintes: o contar } \\
\text { história sem uso da voz }\end{array}$ & 2016 & DISS & Educação de Surdos \\
\hline $\begin{array}{l}\text { Mônica de Nazaré } \\
\text { Carvalho }\end{array}$ & $\begin{array}{c}\text { Tessitura de muitas vozes: as interações } \\
\text { sociais de jovens e adultos com deficiência } \\
\text { intelectual }\end{array}$ & 2017 & DISS & $\begin{array}{c}\text { Educação especial e } \\
\text { Educação de Jovens e } \\
\text { Adultos (EJA) }\end{array}$ \\
\hline $\begin{array}{c}\text { Janiby Silva de } \\
\text { Oliveira }\end{array}$ & $\begin{array}{c}\text { Prática pedagógica do professor com o } \\
\text { aluno autista no contexto da escola } \\
\text { inclusiva }\end{array}$ & 2017 & DISS & $\begin{array}{l}\text { Educação de autistas/ } \\
\text { Práticas pedagógicas } \\
\text { para inclusão nos anos } \\
\text { iniciais do ensino } \\
\text { fundamental }\end{array}$ \\
\hline $\begin{array}{l}\text { Jennifer Souza } \\
\text { Nascimento }\end{array}$ & $\begin{array}{l}\text { Contato improvisação e movimento } \\
\text { Criativo: proposta e prática educativa em } \\
\text { dança para corpos eficientes }\end{array}$ & 2017 & DISS & $\begin{array}{c}\text { Educação Especial na } \\
\text { perspectiva da } \\
\text { Educação Inclusiva }\end{array}$ \\
\hline $\begin{array}{l}\text { Josivan João } \\
\text { Monteiro Raiol }\end{array}$ & $\begin{array}{c}\text { Práticas de letramento de pessoas com } \\
\text { deficiência em um bairro da ilha de } \\
\text { Caratateua/PA }\end{array}$ & 2017 & DISS & $\begin{array}{l}\text { Educação especial e } \\
\text { práticas de Leitura, } \\
\text { Escrita e linguagem }\end{array}$ \\
\hline $\begin{array}{l}\text { Sandy da } \\
\text { Conceição Dias }\end{array}$ & $\begin{array}{l}\text { O ensino de matemática para estudantes } \\
\text { cegos por meio de sistema suplementar de } \\
\text { comunicação }\end{array}$ & 2018 & DISS & $\begin{array}{c}\text { Educação especial, } \\
\text { Ensino de Ciência e } \\
\text { Educação } \\
\text { Matemática/ } \\
\text { Educação de } \\
\text { deficientes visuais }\end{array}$ \\
\hline
\end{tabular}




\begin{tabular}{|c|c|c|c|c|}
\hline $\begin{array}{c}\text { Aneska Silva de } \\
\text { Oliveira }\end{array}$ & $\begin{array}{c}\text { As relações interpessoais no processo de } \\
\text { escolarização de educandos com deficiência } \\
\text { múltipla }\end{array}$ & 2018 & DISS & $\begin{array}{c}\text { Psicologia Escolar e } \\
\text { Educacional e } \\
\text { Inclusão }\end{array}$ \\
\hline $\begin{array}{c}\text { Carla da Silva } \\
\text { Mota }\end{array}$ & $\begin{array}{c}\text { Surdos bilíngues bimodais- um estudo de } \\
\text { caso sobre as interações comunicacionais } \\
\text { entre surdos falantes nativos e falantes } \\
\text { tardios }\end{array}$ & 2019 & DISS & Educação de Surdos \\
\hline $\begin{array}{c}\text { Kátia Maria dos } \\
\text { Santos Dias } \\
\text { Práticas pedagógicas de professores em } \\
\text { escolas da semec-Belém }\end{array}$ & 2019 & DISS & $\begin{array}{c}\text { Práticas pedagógicas } \\
\text { para inclusão na } \\
\text { Educação Infantil }\end{array}$ \\
\hline $\begin{array}{c}\text { Simone de Jesus } \\
\text { da Fonseca } \\
\text { Loureiro }\end{array}$ & $\begin{array}{c}\text { Relações de alteridade: narrativas de/sobre } \\
\text { alunos com deficiência intelectual }\end{array}$ & 2019 & DISS & $\begin{array}{c}\text { Psicologia Escolar e } \\
\text { Educacional e } \\
\text { Inclusão }\end{array}$ \\
\hline $\begin{array}{c}\text { Vera Lúcia de } \\
\text { Cristo Lobato }\end{array}$ & $\begin{array}{c}\text { Afirmaçónes étnicas, conflitos culturais, } \\
\text { paradigmas educativos e estratégias } \\
\text { dialógicas }\end{array}$ & 2019 & DISS & $\begin{array}{c}\text { Educação Especial e a } \\
\text { temática }\end{array}$ \\
\hline
\end{tabular}

Fonte: Elaborado pelos autores com base nas informações do Programa de Pós-graduação em Educação da Universidade do Estado do Pará (2020).

Sobre as áreas temáticas identificadas nas monografias mapeadas, elaborou-se o gráfico a seguir:

gráfico I - Áreas temáticas das dissertações em educação especial defendidas no programa de pósgraduação em educação da UEPA (2016-2019)

\section{Educação de Surdos}

Educação especial e práticas de Leitura, Escrita e linguagem

Psicologia Escolar e Educacional e Inclusão

Formação e prática docente para a educação especial e inclusão

Educação especial e Educação de Jovens e Adultos (EJA)

Práticas pedagógicas para inclusão nos anos iniciais do ensino fundamental

Educação especial, Ensino de Ciência e Educação Matemática

Educação especial e a temática Etnicorracial

Educação Especial na perspectiva da Educação Inclusiva

Educação de deficientes visuais

Educação de autistas

Práticas pedagógicas para inclusão na educação infantil

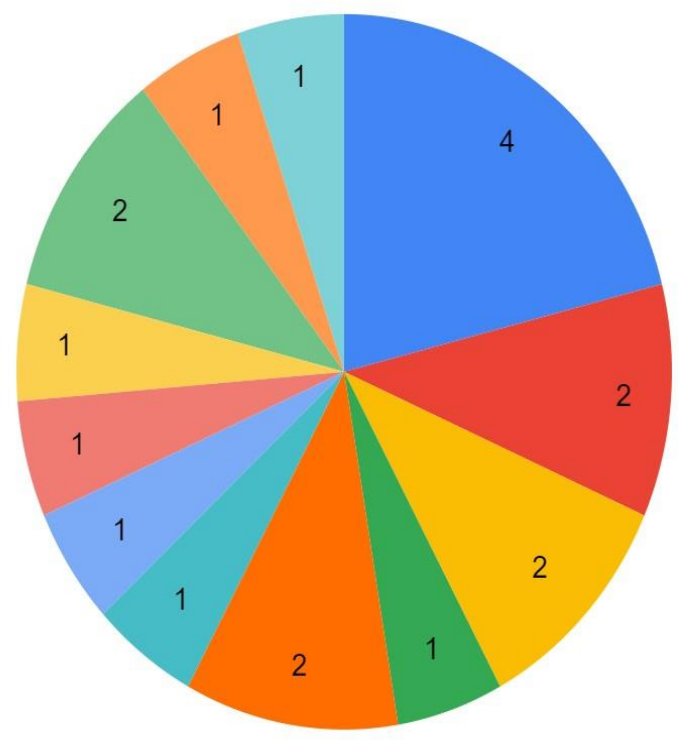

Fonte: Elaborado pelos autores. 


\section{DISCUSSÕES}

Para dar início às discussões, é importante considerar algumas informações preliminares referente ao volume dos trabalhos levantados. Consideramos que: "desde os anos 1980, quando pesquisadores desse campo começaram a avaliar os estudos produzidos, até os dias atuais, várias pesquisas foram desenvolvidas na perspectiva de avaliar o conhecimento produzido pela área" (HAYASHI, 20II, p. 147). Entende-se que tais conhecimentos, abarcam o que tem sido produzido nas teses e dissertações dos programas de Pós-graduação que trabalham com o tema Educação e suas vertentes (NAZARI, 2019).

Do total de 199 trabalhos defendidos no PPGED/UFPA, I2I dissertações e 78 teses, no período destacado no quadro I, apenas 7 , que representam 3,51\%, se concentram na esfera da Educação Especial (quadro 2 e 3). Destaca-se que a representatividade de dissertações com o percentual de 4,95\% das que abordam este tema é maior que a de teses que atingem 1,28\% desses trabalhos (quadro 3). Do total de 162 dissertações defendidas no PPGED/UEPA, no período levantado (quadro I), apenas 15 , que indicam 9,25\% se concentram no campo analisado (quadro 2 e 3).

O tema Educação Especial na amostra total dos 36I trabalhos defendidos em ambos programas é de um percentual de 6,09\% que significam um total de 22 trabalhos (quadro 1, 2 e 3), apontando uma baixa incidência do tema nos quatro anos destacados, com menor índice no PPGED/UFPA, onde o percentual se mostra na casa de 3,51\%, ou seja, apenas 7 trabalhos do total de 199 dissertações e teses (quadro 2 e 3).

O quadro 4 nos mostra a ausência de monografias no campo da Educação Especial no ano de 2018, que é seguido de um leve aumento no ano de 2019 para apenas um único trabalho defendido, marcando a escrita de dissertações e teses nessa área por algumas oscilações e apresentando baixa consolidação, que possivelmente estão associadas a uma diminuta produtividade. O quantitativo anual de monografias defendidas, específicas ao assunto Educação Especial, oscila de forma menos atenuante - e/ou gradual - no PPGED/UEPA (quadro 5), isto implica dizer que pode haver uma maior consolidação e ampliação da produção de trabalhos que concentrem sua problemática na Educação Especial dentro deste programa.

Importa destacar que, os escopos dos Programas de Pós-graduação em Educação, tanto da UEPA como da UFPA, propõem uma abordagem da Educação em uma dimensão mais ampla e, que por assim ser, se torna por vezes mais complexa, mas que dentro dessa proposta possa trazer à luz uma compreensão que abarque seus múltiplos determinantes, nexos e contradições, e a explorar fatores emergentes e importantes nessa composição como, por exemplo, a interdisciplinaridade com que a educação pode ser versada. Assim, notou-se que nestes 
programas tem se valorizado além de tudo, pensar a especificidade da Amazônia Paraense, em particular do Estado do Pará, sob variados contextos socioculturais e políticos, perpassando tanto pela formação docente como pelas teorias e práticas pedagógicas de ensino.

Nessa perspectiva reafirmamos o que tem sido proposto por Mazotta (1997) ao enfatizar que para a efetivação da proposta da Educação Especial no cenário educacional é necessário a fundamentação dos princípios educacionais (MARQUES et al, 2008) de forma direcionada a

viabilizar esse fim, com a proposição de possibilitar o desenvolvimento individual de cada aluno (MAZOTTA, 1997). Entendemos que para que esta fundamentação ocorra as pesquisas de aprofundamento desenvolvidas pelos programas de pós-graduação são essenciais, visto que, delas emergem investigações relacionadas a questões pedagógicas que apresentam um caráter formativo e, portanto, somatório, pois devido serem realizadas periodicamente, atualizam o debate nesta esfera de conhecimento, permitindo que a análise das teorias de aprendizagem e desenvolvimento nas mais diversas situações educacionais sejam discutidas e ampliadas (MARQUES et al, 2008; NAZARI, 2019).

Evidencia-se que discussões na esfera da Educação Especial possibilitam reflexões sob olhares diversos em torno da sua configuração e contexto proposto nos escopos dos programas de Pós-graduação (NAZARI, 2019) de cada uma das instituições, isto é, tornam possíveis o desenvolvimento de diferentes conceitos do prisma da Educação Especial, dando destaque a Amazônia Paraense. Convém considerar ainda que os dados revelam que o estudo da Educação Especial ocorre nas mais diferentes áreas temáticas nos programas analisados.

A verificação dos temas abordados, com base nos resultados obtidos dos dois programas, indica a maior incidência de estudos na área temática Educação dos Surdos com um total de quatro monografias que trabalham de forma isolada o tema e representam $18,18 \%$ dos trabalhos na área (quadro 4 e 5). O mesmo também aparece de forma associada ao tema Educação Especial e a Temática Etnicorracial, que representa 4,54\% do total de trabalhos, sendo evidenciado em apenas uma dissertação. A categoria Educação de deficientes visuais é abordada de forma isolada em uma dissertação (4,54\%), porém é associada a outras duas esferas temáticas: Educação Especial e práticas de Leitura, Escrita e linguagem, que representa 9, 09\% (2 dissertações) do cerne total de trabalhos, e Educação Especial, Ensino de Ciência e Educação Matemática que é presente em uma monografia e apresenta percentual de 4,54\% em relação ao valor total de produção na área (quadro 4 e 5 ).

As áreas temáticas Psicologia Escolar e Educacional e Inclusão; Educação Especial e Educação de Jovens e Adultos; Formação e Prática docente para a educação especial e inclusão; e Práticas pedagógicas para inclusão na educação infantil apresentam o quantitativo de dois 
trabalhos, representando 9,09\% da produção em educação especial. Se distribuem de forma igual - I trabalho e percentual de 4,54\% (quadro 4 e 5 ) - as seguintes áreas temáticas trabalhadas de formas isoladas: Educação Especial e Currículo; Educação, inclusão e trabalho; Políticas públicas de inclusão educacional e atendimento especializado; e Educação Especial na perspectiva da Educação Inclusiva. A categoria Práticas pedagógicas para inclusão nos anos iniciais do ensino fundamental representa os mesmos números, porém, é abordada em associação com o tema Educação de Autistas. Essas informações, portanto, sintetizam a visão global dos temas enfocados na proposta inicialmente apresentada.

Convém destacar que, ao objetivar uma abordagem da educação em uma dimensão mais ampla sob variados contextos, dentre estes os socioculturais e políticos, que perpassam tanto pela formação docente como pelas teorias e práticas pedagógicas de ensino, o debate sobre a Educação Especial, bem como da inclusão dos alunos que necessitam desse suporte, tende a emergir como uma das vias de repercussão política e social estabelecida, e a partir dele, é possível considerar as situações paralelas dos contextos que necessitam da implementação de uma educação especializada (MARQUES et al, 2008; NAZARI, 2019).

O estudo indicou uma tendência maior para a Educação Inclusiva, porém compreendese que essa perspectiva abarca processos mais amplos que evidenciam a Educação Especial como um elemento presente nesse espectro, visto que por ser uma modalidade de ensino, a Educação Especial é necessária para o suporte pedagógico no atendimento da Pessoa Com Deficiência (PCD).

Foram evidenciados campos específicos ainda não investigados, isto é, temáticas ausentes nas dissertações ou teses que entendemos como relevantes e que se encontram envoltos nas especificidades da Educação Especial, como pode-se propor, por exemplo, os temas referentes a abordagens sobre Tecnologias Digitais da Informação e Comunicação (TDICS), Educação e Inclusão Digital, Direitos Humanos e Educação Inclusiva, Educação Popular e Inclusão, Educação do Campo e Inclusão, História da Educação Especial e Inclusão, Educação especial, inclusão e sua relação com a temática de gênero, Educação Emocional e

Inclusão, Educação de alunos com altas habilidades/superdotação.

Esses temas propostos direcionam-se a problemas já estabelecidos, porém referem-se também a situações emergentes na Educação (MARQUES et al, 2008; NAZARI, 2019), faz-se necessário pontuar que a ausência destes temas pode evidenciar a existência de possíveis lacunas nas pesquisas dos PPGED relacionadas a Educação Especial, e sugerem necessidades a serem preenchidas por futuras pesquisas. 


\section{CONSIDERAÇÕES FINAIS}

Ao mapear a produção científica na área de Educação Especial, tendo por objeto as dissertações e teses dos programas de Pós Graduação, não se intencionou realizar um posicionamento crítico em relação aos trabalhos e suas abordagens, mas identificar o que foi produzido e as demandas a que se direcionam a produção do conhecimento nesses programas. Nesse sentido, a seleção e análise dos achados desta pesquisa buscou demonstrar indicadores que pudessem representar o panorama da Educação Especial nas dissertações e teses defendidas nos dois Programas de Pós-graduação em Educação do Pará. Em relação a relevância da pesquisa na pós-graduação pontua-se que a mesma adquire cada vez mais importância e impacto diante da comunidade científica tornando inquestionáveis as contribuições do conhecimento produzido nesses programas. Diante disso, admite-se que essas pesquisas permitem explicitar o alcance, o significado e o papel a que se destinam as pesquisas desenvolvidas sobre Educação Especial na esfera educacional brasileira

Os trabalhos relativos aos quatro anos indicados, apontam nessas produções temas importantes e amplos em sua prevalência, todavia notam-se ausentes a exploração de temas mais específicos sobre a Educação Especial, o que ajuda a identificar possíveis direcionamentos e tendências, assim como lacunas que esse campo vem desenvolvendo nessas produções, revelando não só os avanços recentes na proposição de temas educacionais, e da ampliação de saberes que envolvem as produções científicas que findam por diversificar as possibilidades de soluções de problemas emergentes relacionados às demanda que envolvem a Educação Especial, somando ao conhecimento que já se encontra produzido, novas investigações nessa área.

Ao se perceber a escassez de trabalhos desenvolvidos sob o prisma dessa temática, aponta-se a necessidade de estímulos ao desenvolvimento de pesquisas e à produção científica nessa área em seus diversos segmentos. Isso nos leva a concluir que o número de teses e dissertações defendidas no campo da Educação Especial ainda representam um número pequeno do cerne total destes programas e ressaltam a importância de projetos de pesquisa que valorizem essa temática. Esses estímulos são extremamente necessários para se desvelar dificuldades nas tratativas dos sujeitos que necessitam de especificidades educativas para seu desenvolvimento integral. A ausência de investigações nesse sentido, podem produzir falhas no momento de se compor práticas educativas que envolvam um tratamento específico para a solução de problemas inerentes a educação especializada.

Apesar das limitações próprias da pesquisa, percebe-se que os resultados e discussões advindos deste estudo possam vir a contribuir para o desenvolvimento da discussão acerca do objeto enfocado nas produções monográficas dos Programas de Pós-Graduação em Educação das 
respectivas instituições de ensino. Sugere-se, portanto, que se houver uma preocupação em intensificar a produção acadêmica neste campo, ampliam-se as vias de discussão sobre o conhecimento em pesquisas de aprofundamento, e de acordo com a pesquisa acredita-se que a sistematização e análise da produção acadêmica sobre Educação Especial evidenciada neste estudo seja uma contribuição para fazer avançar a produção de conhecimento na referida área.

\section{REFERÊNCIAS}

BRASIL. Ministério da Educação. Lei no 9.394, de 20 de dezembro de 1996. Estabelece as diretrizes e bases da educação nacional, 1996. Disponível em:

http://portal.mec.gov.br/seed/arquivos/pdf/tvescola/leis/lein9394.pdf. Acesso em: to de julho de 2020 .

COMTE, A. Curso de Filosofia Positiva. Tradução de José Arthur Giannotti. São Paulo: Abril, 1973.

DEMO, P. Cuidado Metodológico. Sociedade e Estado. Brasília, v. 17, n. 2, p. 333-348, 2002.

FALBO, R. A. Mapeamento sistemático. Vitória: Universidade Federal do Espírito Santo, 2018. Disponível em: http://www.inf.ufes.br/ falbo/files/MP/TP/Sobre_MS.pdf. Acesso em: 25 de março de 2020 .

GATTI, B. Estudos quantitativos em educação. Educação e Pesquisa, São Paulo, v. 3o, n. I, p. II30, 2004 .

HAYASHI, M. C. P. I. Múltiplos olhares sobre a produção do conhecimento em educação especial. Revista Diálogo Educacional, Curitiba, v. II, n. 32, p. I45-165, jan./abr. 2011.

KASSAR, M. C. M. Educação especial na perspectiva da educação inclusiva: desafios da implantação de uma política nacional. Educar em Revista, Curitiba, Brasil, n. 4I, p. 61-79, Editora UFPR, 20II.

MARQUES, L. P., CARNEIRO, C. T., ANDRADE, J. D. S., MARTINS, N. T., \& GONÇALVES, R. M. Analisando as pesquisas em educação especial no Brasil. Revista Brasileira de Educação Especial, v. I4, n. 2, p. 251-272, 2008.

MAZZOTTA, M.J.S. Educação escolar: comum ou especial. São Paulo: Martins Fontes, 1987.

Educação especial no Brasil: história e políticas públicas. 5. ed. São Paulo: Cortez, 2005.

NAZARI, A. C. G. Educação Especial na Produção Acadêmica do PPGED/UFU: das contradições às proposições. Tese (Doutorado). Programa de Pós Graduação em Educação, Universidade Federal de Uberlândia, 2019.

PPGED UEPA, Programa de Pós Graduação em Educação da Universidade do Estado do Pará UEPA/CCS, Dissertações de Mestrado Defendido, 2020. Disponível em: 
http://ccse.uepa.br/ppged/?page_id=65o. Acesso em: 28 de março de 2020.

REPOSITÓRIO DA UFPA, Repositório Institucional da Universidade Federal do Pará, Biblioteca Central UFPA/SIBI, 2020. disponível em: http://repositorio.ufpa.br/jspui/. Acesso em: 28 de março de 2020 . 